Original article

\title{
The Role of Urban Environment, Social and Health Determinants in the Tracking of Leisure-Time Physical Activity Throughout Adolescence
}

\author{
Alexandre Pedro Tavares da Fonseca Magalhães, M.P.H. ${ }^{\text {a,b,c,d, }}$ \\ Maria de Fátima Rodrigues Pereira de Pina, Ph.D. ${ }^{\text {b,c,e,f }}$, and \\ Elisabete da Conceição Pereira Ramos, Ph.D. ${ }^{\text {a,g,* }}$ \\ ${ }^{a}$ Departamento de Epidemiologia Clínica, Medicina Preditiva e Saúde Pública, Faculdade de Medicina da Universidade do Porto, Porto, Portugal \\ ${ }^{\mathrm{b}}$ I3S-Instituto de Investigação e Inovação em Saúde, Universidade do Porto, Porto, Portugal \\ c INEB - Instituto de Engenharia Biomédica, Universidade do Porto, Porto, Portugal \\ ' ISPUP, Instituto de Saúde Pública da Universidade do Porto, Porto, Portugal \\ e Instituto de Comunicação e Investigação Científica e Tecnológica em Saúde, Fundação Oswaldo Cruz-ICICT/FIOCRUZ, Rio de Janeiro, Brazil \\ ${ }^{\mathrm{f}}$ CARTO-FEN/UERJ, Departamento de Engenharia Cartográfica, Faculdade de Engenharia, Universidade do Estado do Rio de Janeiro, Rio de Janeiro, Brazil \\ ${ }^{g}$ EPIUnit, Instituto de Saúde Publica da Universidade do Porto, Porto, Portugal
}

Article history: Received December 20, 2015; Accepted August 13, 2016

Keywords: Leisure-time physical activity; Cohort study; Adolescence; Urban green space; Open sports space

\section{A B S T R A C T}

Purpose: Adolescence may be a period particularly relevant for acquisition of lifelong habits of physical activity (PA). We investigated the tracking of leisure-time PA from 13 to 17 years old and the influence of urban environment and other determinants.

Methods: As part of the EPITeen cohort (Portugal), we evaluated 969 adolescents living in the city of Porto. Participants were assembled in public and private schools at 13 years and reevaluated at 17 years. Leisure-time PA was evaluated by self-reported questionnaires. The shortest routes from residence to urban green spaces and open sports spaces were calculated using the street network within a Geographical Information System. Odds ratio (OR) and 95\% confidence intervals were calculated by multinomial logistic regression.

Results: Among sedentary girls at 13 years, 33.1\% were still sedentary at 17 years, $39.8 \%$ changed to low, $22.3 \%$ to moderate, and only $4.6 \%$ changed to vigorous PA. In boys, the respective values were $32.3 \%, 17.3 \%, 36.2 \%$, and $14.2 \%$. High PA levels were maintained by $19.5 \%$ of the girls and by $41.1 \%$ of the boys. After adjustment for parental education and body image at 13 years, practice of sports at 13 years was strongly associated with stable high PA at 17 years: in girls $\mathrm{OR}=3.96(2.21,7.12)$; in boys $\mathrm{OR}=6.81(3.30,14.07)$. Distance to urban green spaces or to open sports spaces was not associated to changes in leisure-time PA.

Conclusion: Practice of sports in early adolescence may be important to promote maintenance of high PA. Urban environment in the vicinity of residence did not affect changes in the practice of leisure-time PA.

(c) 2016 Society for Adolescent Health and Medicine. All rights reserved.

\section{IMPLICATIONS AND} CONTRIBUTION

This study adds information on the tracking of leisure-time physical activity throughout adolescence and on the main characteristics that influence its changes. Urban environment did not affect observed changes in the levels of PA throughout adolescence. Practice of sports at 13 years was the major determinant of high PA throughout adolescence.

\footnotetext{
Conflicts of Interest: A.P.T.d.F.M., E.d.C.P.R., and M.d.F.R.P.d.P. declare that they have no conflict of interest.

* Address correspondence to: Elisabete da Conceição Pereira Ramos, Ph.D., ISPUP, Rua das Taipas, 135, Porto 4050-600, Portugal.

E-mail address: eliramos@med.up.pt (E.d.C.P. Ramos).
} 
Physical inactivity is one of the eight risk factors whose reduction would increase global life expectancy [1]. Adolescence is a very important period since it is a timing of acquisition of physical activity (PA)-related behaviors that extend to adult life $[2,3]$. However, globally, the proportion of 13 - to 15 -year-old adolescents practicing less than 60 minutes of moderate to vigorous PA per day is above $80 \%$, and the prevalence is higher among girls [4]. Additionally, there is a sharp decline in intensity of PA throughout adolescence [5,6].

Improving PA in young people is a priority to achieve direct health benefits and also to increase self-esteem, self-expression, self-confidence, and assertiveness, factors considered potential determinants of health-related behaviors [7-9].

Various domains of activity contribute to adolescents PA levels: school activities, transport-related, domestic, and leisuretime activities. However, since most of the adolescents' day is spent at school on sedentary activities (e.g., seated in classes), leisure-time activities are the main contributors to the differences in PA among adolescents [10,11]. So, it is certainly important to understand the factors that influence leisure-time PA throughout adolescence.

The urban environment, both the natural and built, can influence leisure-time PA, namely by providing sports spaces, green spaces, and parks, which increase the opportunity to practice leisure-time PA in children and/or adolescents [12,13]. Previous studies about the association between urban environment and PA showed contradictory results: several studies showed that the urban environment is a determinant of PA $[5,14]$; however others did not find any association $[15,16]$. Additionally, most of those studies are cross sectional [17], and results need to be confirmed using a longitudinal approach $[5,18]$. On the other hand, the potential effect of the urban environment may differ at different ages [12], since children and young adolescents are less autonomous than older adolescents. Therefore, with increasing autonomy throughout adolescence, mobility increases, and this might reduce the effect of not having facilities closer to home.

Our aim is to understand, through a longitudinal study, how leisure-time PA changes from early to late adolescence (from 13 to 17 years old) and to evaluate how the urban environment and other determinants influence it.

\section{Methods}

\section{Participants}

Eligible participants were adolescents from the Epidemiological Health Investigation of Teenagers in Porto cohort. As previously reported [19], in 2003/2004, we assembled a cohort of adolescents born in 1990 and enrolled at public and private schools in Porto, Portugal. The second evaluation took place in the $2007 / 2008$ school year.

At baseline, 2,159 adolescents agreed to participate (77.5\% of participation). Four years later $79.4 \%$ participants were reevaluated. For this analysis, we excluded participants who do not live in Porto $(n=612)$. From the 1,547 living in Porto, 244 were lost to follow-up and 334 had missing data on leisure-time PA or sports in at least one of the evaluations. Our final sample comprises 969 participants. Those who were lost to follow-up had parents with lower education [mean (standard deviation) 8.6 (4.4) years of school attainment vs. 10.9 (4.7), $p<.001$ ], had lower proportion of sports practitioners $(p<.001)$, but no differences were found regarding distances to urban green spaces (UGS) or open sports spaces (OSS).

\section{Data collection}

Both evaluations followed similar procedures [19]. Data were collected using self-administered questionnaires, comprising information on individual and family history of disease, behavioral, social, and demographic characteristics.

\section{Tracking of leisure-time physical activity}

Self-perception of leisure-time PA was evaluated using the question: "How do you spend your leisure-time out of school activities?" Four closed response options were provided: most of the time sitting (sedentary); the majority of the time standing up or walking, without running (low); half of the time standing up and the rest running or playing (moderate); the majority of the time running or playing (vigorous).

A validity study was developed in a sample of 209 participants (57.4\% girls), aged from 14 to 18 years. Those participants did not participate in the Epidemiological Health Investigation of Teenagers in Porto cohort but attended schools in Porto. We compared self-reported data with objective measures obtained on seven consecutive days by Actigraph accelerometers, model GT1M (Actigraph LLC Pensacola, FL). The correlation between methods was .42 for girls and .46 for boys, which are in line with a systematic review that found a median validity coefficients ranging from .30 to .39 [20].

Adolescents who reported spending the majority of the time sitting, standing up, or walking (the first two answer options) were grouped and classified as light PA, those reporting the two other options were classified as moderate/vigorous PA. Based on these two groups, we classified PA changes between 13 and 17 years: those with light PA at both moments-stable light (reference category); those who changed from light to moderate/vigorous PA-increasing; those who changed from moderate/vigorous to light PA-decreasing; and those with moderate/vigorous PA at both moments-stable high.

\section{Other self-reported variables}

Sports practice was considered if the participant reported practicing sports activities outside the compulsory school curriculum.

Participation in sports competitions was evaluated using a question with five closed response options: never participated; do not participate now, but had already participated; yes, interscholastic; yes, in a club; yes, at a national and/or international level. For our analysis, we grouped the three last answers in a single category, comprising adolescents that participated in any sports competition at 13 years.

Transportation between school and home was classified in both waves as "No Active" if adolescents used bus, car, or motorcycle and as "Active" if they walked or cycled to school.

In both waves, smoking was collected by self-reported questionnaires. Combining data from both waves, adolescents were classified into three categories: "no smokers" if they had never smoked; "starting before 13 years" if they reported they had smoked or experienced at 13 years; and "starting after 13 years" if they reported they had not smoked at 13 years, but they reported to smoke at 17 years. 
We used educational attainment of the parents as a proxy of socioeconomic status. Educational attainment was obtained through a questionnaire filled in by the parents at home. Parental educational level was measured as the number of successfully completed years of formal schooling, and we considered the information from the parent with the highest education level. Participants were classified in four classes: $\leq 6$ years; $7-9$ years; 10-12 years; and $>12$ years.

In both waves, data on previous diagnosis of diseases and usual medication were collected. Additionally, information about other specific diseases, such as diabetes, asthma, and rhinitis was assessed.

In both waves, body image perception and ideal image were determined using body shape representation from a figure rating scale-The Stunkard figures [21]. The figure rating scale consists of a series of nine figure drawings. Each of the nine figures was scored from 1 to 9 , with " 1 " representing the most slender figure and " 9 " representing the heaviest figure. Body image dissatisfaction was defined by the discrepancy between perceived current and ideal figures (current figure rating minus ideal figure rating). Based on the difference between perceived and desired body images, we defined three classes: no discrepancy between current and ideal body image (satisfied); an ideal figure larger than current (too thin); and an ideal figure thinner than current (too large) [22].

\section{Anthropometrics}

In both waves, a physical examination was performed at school by a trained team under standard procedures, with the participant in light clothing and barefoot [23]. Weight was measured using bioimpedance equipment (Tanita TBF-300, Tanita Corporation of America, Inc., IL), with the participant on the center of the platform with the weight distributed equally on both feet. For height, a portable stadiometer was used. Adolescents were classified according to age- and sex-specific body mass index (BMI) reference percentiles from the U.S. Centers for Disease Control and Prevention [24]. Participants were considered overweight if BMI was at or above the 85th and below the 95th percentile and obese when BMI was at or above the 95th percentile [23].

Mother's and father's self-reported weight and height were obtained by a questionnaire filled in at home by the parents, and BMI was classified according to WHO classification [25]. Parents whose BMI was $\leq 24.9 \mathrm{~kg} / \mathrm{m}^{2}$ were considered normal weight, those with BMI $>24.9$ to $<30.0 \mathrm{~kg} / \mathrm{m}^{2}$ were considered overweight, and those with BMI $\geq 30.0 \mathrm{~kg} / \mathrm{m}^{2}$ obese. For our analysis, we grouped overweight and obesity in one category.

\section{Residence and urban facilities georeferencing}

Participants' residential addresses were georeferenced by interpolation in street segments using a Geographical Information System.

Urban green spaces. We considered UGS the portions of land with plant species in the urban context, such as parks or gardens. We obtained a digital map from the city council of all the existing UGS in Porto, and we selected those with an area $\geq 2,000 \mathrm{~m}^{2}(\mathrm{n}=71)$. By a field survey, we evaluated which UGS had adequate facilities for physical or sports activities, such as plain areas for group sports or paths for walking, running, or cycling. We excluded 9 green spaces because of steep gradients, 14 because they were run-down areas, and 22 because they were private green spaces without free access. Thus, 26 UGS remained for our study.

For green spaces without walls or fences, we used Geographical Information System to calculate the distance between the residence and the green space, using the street network to identify the closest path; for those green spaces that were delimited by a wall or fence, we georeferenced the entrances using Global Positioning System (GPS) devices and calculated the distance, by the closest path, between the residence and the closest entrance of the green space.

Open sports spaces. OSS were all outdoor public or private facilities for sports practice, with access free of charge and which did not require registration. A total of 46 OSS were reported by the city council and georeferenced using GPS, at the centroid of the space when no wall or fence existed and in the entrance when they were delimited by a wall or a fence, using a GPS.

Distance quantification. The shortest routes from residence to the nearest UGS and OSS were calculated using the street network, considering the density of street intersections and the accentuated elevation differences leading to streets with high slopes. We classified distance into three categories: $\leq 400 \mathrm{~m}$; $>400 \mathrm{~m}$ to $\leq 800 \mathrm{~m}$; and $>800 \mathrm{~m}$, corresponding respectively to a walking time of 5 or less minutes, $6-10$ minutes, and more than 10 minutes [26].

\section{Statistical analysis}

The qui-square test was used to compare proportions between classes of PA and independent variables at 13 years and 17 years. The McNemar test was used to compare changes in PA from 13 to 17 years.

Associations between changes in leisure-time PA, adjusted for parental education and body image, were measured using odds ratio and $95 \%$ confidence intervals calculated by a multinomial logistic regression. All variables presented in the tables were tested as possible confounders. We started with a global model including all those variables, and then we excluded variables step by step (backward) until we reached the model that presented the best fit (the final model only included body image). However, since our previous studies in this sample showed a strong effect of parental education, and since its inclusion did not change the fit of the model, we decided to include this variable to control for potential residual confounding. Therefore, our final model included body image and parental education. All the analyses were stratified by sex and performed on Statistical Package for the Social Sciences for Windows, version 20.

\section{Ethical considerations}

The study was approved by the Ethics Committee of Hospital São João. Policies and procedures were developed to guarantee data confidentiality and protection. Parents and adolescents received written and oral information explaining the purpose and the design of the study and written informed consent was obtained from both.

\section{Results}

In both study waves, the proportion of boys reporting moderate/vigorous leisure-time PA was significantly higher than the 
Table 1

Proportion of changes in leisure-time physical activity from 13 to 17 years, by sex

\begin{tabular}{lcccc}
\hline Physical activity at 13 years & \multicolumn{5}{c}{ Physical activity at 17 years } \\
\cline { 2 - 5 } & Sedentary & Low & Moderate & Vigorous \\
\hline Girls & 33.1 & 39.8 & 22.3 & 4.8 \\
$\quad$ Sedentary & 18.3 & 52.9 & 24.2 & 4.6 \\
$\quad$ Low & 14.5 & 39.9 & 29.0 & 16.7 \\
$\quad$ Moderate & 7.5 & 34.3 & 34.3 & 23.9 \\
$\quad$ Vigorous & & & & \\
Boys & 32.3 & 17.3 & 36.2 & 14.2 \\
$\quad$ Sedentary & 18.2 & 34.5 & 32.7 & 14.5 \\
$\quad$ Low & 17.6 & 14.4 & 40.5 & 27.5 \\
$\quad$ Moderate & 10.2 & 17.6 & 38.9 & 33.3 \\
$\quad$ Vigorous & & & & \\
\hline
\end{tabular}

proportion of girls ( $58.9 \%$ vs. $41.1 \%, p<.001$ at 13 years, and $61.4 \%$ vs. $38.6 \%, p<.001$ at 17 years). The decrease in leisure-time PA from 13 to 17 years was higher among females. Table 1 shows the changes in self-perceived leisure-time PA between 13 and 17 years, by sex. Approximately $53 \%$ of girls and $35 \%$ of boys that were low active at 13 years remained low active at 17 years. Among moderately active adolescents at 13 years, 55\% of girls and one-third of boys decreased their leisure-time PA, and only $17 \%$ of girls and $28 \%$ of boys increased to vigorous activity. Among adolescents that reported vigorous leisure-time PA at 13 years, only $24 \%$ of girls and $33 \%$ of boys remained vigorous at 17 years. However, the differences did not reach statistical significance ( $p=.348$ for girls and $p=.443$ for boys).

In both sexes, no significant effect on leisure-time PA changes was observed according to previous diagnosis of asthma and rhinitis and categories of BMI. Significant differences were found in both sexes regarding perception of body image, sports practice, and means of transportation at 13 years. We found a higher proportion of adolescents in the category Stable Light among those who perceived themselves as too large; additionally, a higher proportion of decreasing PA in girls and of Stable High in boys was found among those who perceived themselves as too thin. Adolescents who reported to practice sports or participate in sports competitions remained more active. In boys, the proportion of adolescents in Stable Light was higher among those who had never smoked. BMI, body image, and the means of transportation to school at 17 years were not associated with leisure-time PA changes (Table 2).

No differences were found on the distribution of the categories of changes in leisure-time PA according to distance from residence to UGS or to OSS. Additionally, no statistically significant differences were found according to parental education and parents' BMI (Table 3).

After adjustment for parental education and body image at 13 years, in both sexes the practice of sports and the involvement in sports competitions at 13 years was strongly associated with remaining at moderate/vigorous leisure-time PA. Practice of sports at 13 years was also associated with decreasing leisuretime PA, which was explained by the proportion of adolescents that stopped practicing sports during this period (41.2\% in girls and $17.0 \%$ in boys). Higher parental educational level decreased the odds of decreasing leisure-time PA, although reaching statistical significance only in boys. Participants that started smoking before 13 years had higher odds of decreasing leisuretime PA throughout adolescence. No effect was found between the proximity of residence to UGS or to OSS and the changes in leisure-time PA (Table 4).

\section{Discussion}

From early (13 years) to late adolescence (17 years), we found a decrease in leisure-time PA and a high stability specifically in those with low leisure-time PA. Among the determinants of the tracking of leisure-time PA, sports practice at early adolescence, whether it was recreational or competitive, showed to be the most important determinant among those assessed in this study. Participants who practice sports at early adolescence were more likely to present stable high leisure-time PA from 13 to 17 years, both in girls and boys.

Our results are in accordance with previous studies [27] and highlight the importance of promoting the practice of sports early in life, especially among girls. Different reasons may explain the positive effect of early participation in sports. Previous experience with sports may provide to adolescents the opportunity to experience the benefits of being active and may enhance enjoyment and motivation to continue engaged in leisure-time physical activities throughout adolescence [28,29]. It could also be determinant to define peers and the perception of belonging to a group $[8,30]$.

In our study, the urban environment was not associated with changes in leisure-time PA. Since $99.9 \%$ of the adolescents still maintained the same address in the city, and there were no major changes in the urban environment during the follow-up, we believe that the routine of using the available facilities may have been acquired in childhood, and therefore, the increased autonomy from 13 years to 17 years did not change the use of these facilities. Additionally, it is important to consider that the availability of facilities is not the only determinant of utilization [31], and other characteristics such as safety, attractiveness, surface conditions, and accessibility may influence utilization [32]. Nevertheless, we did not have data to explore the effect of those factors.

We must also take into account other characteristics of the city as a potential explanation for the lack of association between the urban environment and leisure-time PA. Porto is a relatively small city ( $10.09 \mathrm{~km}$ length by $4.10 \mathrm{~km}$ width), which makes the greatest distances comparatively short, allowing almost all participants to have a UGS or an OSS close to home. Additionally, the offer of sports spaces in the majority of UGS or OSS is similar, offering facilities more in line with sports generally preferred by boys (football, basketball). Therefore, most boys have the opportunity to practice their favorite sports close to home but most girls do not [33].

We found that higher parental educational level reduced the odds of decreasing leisure-time PA from 13 to 17 years, although it reached statistical significance only in boys. This is a particularly important factor since, besides protecting from the decrease in leisure-time PA throughout adolescence, it also determined a higher probability of practicing sports at younger ages [33].

Health characteristics could also influence PA. Since our study is centered on a population-based sample, a very low prevalence of health-related events was reported, being asthma and rhinitis the most frequently reported diseases. For this reason and because they can influence the choice of leisure-time physical activities [34], we analyzed the association of asthma and rhinitis with changes in PA; however, no association was found.

During this period of life, body image is an important issue $[35,36]$. Although after adjustment the results were not statistically significant, the potential effect of body image on leisuretime PA is an interesting finding of our study. In both sexes, we 
Table 2

Changes in leisure-time physical activity according to history of diseases, body image, and behaviors, by sex

\begin{tabular}{|c|c|c|c|c|c|c|c|c|}
\hline & \multicolumn{4}{|l|}{ Girls } & \multicolumn{4}{|l|}{ Boys } \\
\hline & Stable light & Increasing & Decreasing & Stable high & Stable light & Increasing & Decreasing & Stable high \\
\hline & $230(43.9 \%)$ & $89(17.0 \%)$ & $103(19.7 \%)$ & $102(19.5 \%)$ & $92(20.8 \%)$ & $90(20.3 \%)$ & $79(17.8 \%)$ & $182(41.1 \%)$ \\
\hline \multicolumn{9}{|l|}{ Asthma } \\
\hline No & $204(44.1)$ & 77 (16.6) & $93(20.1)$ & $89(19.2)$ & $73(20.1)$ & $74(20.4)$ & $68(18.7)$ & $148(40.8)$ \\
\hline Yes & $22(44.5)$ & $10(20.0)$ & $8(16.0)$ & $10(20.0)$ & $14(26.9)$ & $9(17.3)$ & $7(13.5)$ & $22(42.3)$ \\
\hline$p$ value & .873 & & & & .583 & & & \\
\hline \multicolumn{9}{|l|}{ Rhinitis } \\
\hline No & $216(45.1)$ & $77(16.1)$ & $94(19.6)$ & $92(19.2)$ & $75(19.8)$ & $75(19.8)$ & $70(18.5)$ & $158(41.8)$ \\
\hline Yes & $10(29.4)$ & $10(29.4)$ & $7(20.6)$ & 7 (20.6) & $12(32.4)$ & $8(21.6)$ & $5(13.5)$ & $12(32.4)$ \\
\hline$p$ value & .161 & & & & .285 & & & \\
\hline \multicolumn{9}{|l|}{ BMI 13 years ${ }^{a}$} \\
\hline$<85$ th percentile & $193(44.5)$ & $71(16.4)$ & $82(18.9)$ & $88(20.3)$ & $73(20.2)$ & $73(20.2)$ & $67(18.5)$ & $149(41.2)$ \\
\hline$\geq 85$ th percentile & $26(40.0)$ & $15(23.1)$ & $13(20.0)$ & $11(16.9)$ & $16(26.2)$ & $13(21.3)$ & $11(18.0)$ & $21(34.4)$ \\
\hline$p$ value & .553 & & & & .673 & & & \\
\hline \multicolumn{9}{|c|}{ Perception of body image at 13 years ${ }^{b}$} \\
\hline Satisfied & $83(39.0)$ & $37(17.4)$ & $42(19.7)$ & $51(23.9)$ & $20(15.6)$ & $31(24.2)$ & $28(21.9)$ & $49(38.3)$ \\
\hline Too thin & $27(38.6)$ & $12(17.1)$ & $23(32.9)$ & $8(11.4)$ & $25(17.1)$ & $25(17.1)$ & $25(17.1)$ & $71(48.6)$ \\
\hline Too large & $94(48.5)$ & $35(18.0)$ & $29(14.9)$ & $36(18.6)$ & $41(32.3)$ & 25 (19.7) & $18(14.2)$ & $43(33.9)$ \\
\hline$p$ value & .018 & & & & .006 & & & \\
\hline \multicolumn{9}{|l|}{ Practice of sports at 13 years } \\
\hline No & $161(53.7)$ & $53(17.7)$ & $51(17.0)$ & $35(11.7)$ & $57(36.5)$ & $42(26.9)$ & $18(11.5)$ & $39(25.0)$ \\
\hline Yes & $68(30.8)$ & $35(15.8)$ & $51(23.1)$ & $67(30.3)$ & $35(12.3)$ & $47(16.5)$ & $59(20.8)$ & $143(50.4)$ \\
\hline$p$ value & $<.001$ & & & & $<.001$ & & & \\
\hline \multicolumn{9}{|c|}{ Sports competition at 13 years } \\
\hline Never practice & $112(53.8)$ & $35(16.8)$ & $36(17.3)$ & $25(12.0)$ & $29(35.8)$ & $18(22.2)$ & $16(19.8)$ & $18(22.2)$ \\
\hline No but already done & $66(42.3)$ & $29(18.6)$ & $30(19.2)$ & $31(19.9)$ & $32(27.8)$ & $33(28.7)$ & $20(17.4)$ & $30(26.1)$ \\
\hline Yes & $39(34.9)$ & $22(18.0)$ & $26(18.4)$ & $35(28.7)$ & $27(13.0)$ & $30(14.5)$ & $37(17.9)$ & $113(54.6)$ \\
\hline$p$ value & .002 & & & & $<.001$ & & & \\
\hline \multicolumn{9}{|c|}{ Transportation to school at 13 years } \\
\hline No active & $92(37.9)$ & $43(17.7)$ & $48(19.8)$ & $60(24.7)$ & $54(25.4)$ & $49(23.0)$ & $27(12.7)$ & $83(39.0)$ \\
\hline Active & $114(49.4)$ & $40(17.3)$ & $43(18.6)$ & $34(14.7)$ & $31(17.3)$ & $30(16.8)$ & $43(24.0)$ & 75 (41.9) \\
\hline$p$ value & .022 & & & & .007 & & & \\
\hline \multicolumn{9}{|l|}{ Smoke habits } \\
\hline Never smoker & $120(45.6)$ & $45(17.1)$ & $45(17.1)$ & $53(20.2)$ & $60(24.9)$ & $49(20.3)$ & $39(16.2)$ & $93(38.6)$ \\
\hline Starting before 13 years & $64(47.1)$ & $19(14.0)$ & $28(20.6)$ & $25(18.4)$ & $10(13.3)$ & $11(14.7)$ & $22(29.3)$ & $32(42.7)$ \\
\hline Starting after 13 years & $46(36.8)$ & $25(20.0)$ & $30(24.0)$ & $24(19.2)$ & $22(17.3)$ & $30(23.6)$ & $18(14.2)$ & $57(44.9)$ \\
\hline$p$ value & .469 & & & & .026 & & & \\
\hline \multicolumn{9}{|l|}{ BMI 17 years ${ }^{a}$} \\
\hline$<85$ th percentile & $182(41.5)$ & $78(17.8)$ & $87(19.8)$ & $92(21.0)$ & $64(18.4)$ & $74(21.3)$ & $60(17.3)$ & $149(42.9)$ \\
\hline$\geq 85$ th percentile & $40(52.6)$ & $11(14.5)$ & $16(21.1)$ & $9(11.8)$ & $27(29.3)$ & $16(17.4)$ & $17(18.5)$ & $32(34.8)$ \\
\hline$p$ value & .166 & & & & .114 & & & \\
\hline \multicolumn{9}{|c|}{ Perception of body image at 17 years $^{\mathrm{b}}$} \\
\hline Satisfied & $122(43.4)$ & $45(16.0)$ & $52(18.5)$ & $62(22.1)$ & $54(19.5)$ & $54(19.5)$ & $48(17.3)$ & $121(43.7)$ \\
\hline Too thin & $19(45.2)$ & $8(19.0)$ & $9(21.4)$ & $6(14.3)$ & $13(16.2)$ & $17(21.2)$ & $12(15.0)$ & $38(47.5)$ \\
\hline Too large & $83(43.0)$ & $36(18.7)$ & $41(21.2)$ & $33(17.1)$ & $22(31.0)$ & $14(19.7)$ & $18(25.4)$ & $17(23.9)$ \\
\hline$p$ value & .786 & & & & .035 & & & \\
\hline \multicolumn{9}{|c|}{ Transportation to school at 17 years } \\
\hline No active & $112(40.3)$ & $54(19.4)$ & $59(21.2)$ & $53(19.1)$ & $52(23.7)$ & $49(22.4)$ & $32(14.6)$ & $86(39.3)$ \\
\hline Active & $90(47.9)$ & $28(14.9)$ & $33(17.6)$ & 37 (19.7) & $31(17.2)$ & $33(18.3)$ & 37 (20.6) & 79 (43.9) \\
\hline$p$ value & .310 & & & & .149 & & & \\
\hline
\end{tabular}

$\mathrm{BMI}=$ body mass index.

a According to 2000 Centers for Disease Control and Prevention Growth Charts for the United States.

b Too Thin-perceived image was thinner than the desired one; Too Large-perceived image was larger than the desired one.

found that participants who perceived their image as too large were less likely to decrease leisure-time PA, and that boys who perceived their image as too thin had higher odds of stable high leisure-time PA. These results support that leisure-time PA is viewed as an instrument to reach the ideal figure, by decreasing weight/fat (among girls and boys) [37] or by increasing muscle among those perceiving their image thinner than the desired one, among boys [38].

The limitations of our study should be acknowledged. The most important of these is that leisure-time PA was based on self-reported questions, which can increase the potential for recall bias based on social desirability. However, in order to evaluate the ability of our question, we compared the question with objective measures and found acceptable correlation coefficients [20]. However, to evaluate the changes between 13 and 17 years, we aggregated the four categories into two, which limits our ability to understand the determinants of small changes in leisure-time PA. This approach limits the precision of our measurements but provides relevant information for the design of population-based interventions to promote PA.

Although, in general, no differences were found between excluded and included participants, a potential selection bias is present since we lost those with lower educated parents and with lower levels of sports. Therefore, those losses may have 
Table 3

Changes in leisure-time physical activity according to distances from residence to urban green spaces (UGS), open sports spaces (OSS), and parents' characteristics, by sex

\begin{tabular}{|c|c|c|c|c|c|c|c|c|}
\hline & \multicolumn{4}{|l|}{ Girls } & \multicolumn{4}{|l|}{ Boys } \\
\hline & Stable light & Increasing & Decreasing & Stable high & Stable light & Increasing & Decreasing & Stable high \\
\hline \multicolumn{9}{|l|}{ Distances to UGS } \\
\hline$>800 \mathrm{~m}$ & $58(38.9)$ & $25(16.8)$ & $36(24.2)$ & $30(20.1)$ & 40 (19.7) & $41(20.2)$ & $33(16.3)$ & $89(43.8)$ \\
\hline$>400 \mathrm{~m}$ to $\leq 800 \mathrm{~m}$ & $69(45.7)$ & $29(19.2)$ & 25 (16.6) & $28(18.5)$ & $25(21.7)$ & $22(19.1)$ & $21(18.3)$ & $47(40.9)$ \\
\hline$\leq 400 \mathrm{~m}$ & $103(46.0)$ & 35 (15.6) & $42(18.8)$ & 44 (19.6) & 27 (21.6) & 27 (21.6) & $25(20.0)$ & $46(38.6)$ \\
\hline $\bar{p}$ value & .632 & & & & .925 & & & \\
\hline \multicolumn{9}{|l|}{ Distances to OSS } \\
\hline$>800 \mathrm{~m}$ & $70(37.6)$ & $36(19.4)$ & $39(21.0)$ & $41(22.0)$ & $31(19.0)$ & $36(22.1)$ & $32(19.6)$ & $64(39.3)$ \\
\hline$>400 \mathrm{~m}$ to $\leq 800 \mathrm{~m}$ & $89(48.4)$ & $32(17.4)$ & $35(19.0)$ & $28(15.2)$ & $35(21.5)$ & $37(22.7)$ & $26(16.0)$ & 65 (39.9) \\
\hline$\leq 400 \mathrm{~m}$ & $71(46.1)$ & $21(13.6)$ & $29(18.8)$ & $33(21.4)$ & $26(22.2)$ & $17(14.5)$ & $21(17.9)$ & $53(45.3)$ \\
\hline $\bar{p}$ value & .301 & & & & .885 & & & \\
\hline \multicolumn{9}{|c|}{ Parental education (years) } \\
\hline$\leq 6$ & $67(48.2)$ & $18(12.9)$ & $30(21.6)$ & $24(17.3)$ & $13(13.8)$ & $16(17.0)$ & $24(25.5)$ & $41(43.6)$ \\
\hline $7-9$ & $48(44.0)$ & $24(22.0)$ & $22(20.2)$ & $15(13.8)$ & $16(20.5)$ & $16(20.5)$ & $15(19.2)$ & $31(39.7)$ \\
\hline $10-12$ & $58(45.0)$ & $24(18.6)$ & $22(17.1)$ & $25(19.4)$ & $29(24.4)$ & $27(22.7)$ & $16(13.4)$ & $47(39.5)$ \\
\hline$\geq 12$ & $57(39.3)$ & $22(15.2)$ & $29(20.0)$ & $37(25.5)$ & $34(22.4)$ & $31(20.4)$ & $24(15.8)$ & $63(41.4)$ \\
\hline$p$ value & .318 & & & & .432 & & & \\
\hline \multicolumn{9}{|c|}{ Mother BMI at 13 years $\left(\mathrm{kg} / \mathrm{m}^{2}\right)$} \\
\hline$\leq 24.9$ & $127(42.3)$ & $53(17.7)$ & $63(21.0)$ & $57(19.0)$ & $52(19.5)$ & $52(19.5)$ & 45 (16.9) & $162(43.3)$ \\
\hline$>24.9$ & $85(47.2)$ & $31(17.2)$ & $28(15.6)$ & $36(20.0)$ & $30(20.5)$ & $35(24.0)$ & $25(17.1)$ & $56(38.4)$ \\
\hline$p$ value & .487 & & & & .652 & & & \\
\hline \multicolumn{9}{|c|}{ Father BMI at 13 years $\left(\mathrm{kg} / \mathrm{m}^{2}\right)$} \\
\hline$\leq 24.9$ & $82(40.8)$ & $37(18.4)$ & $43(21.4)$ & $39(19.4)$ & $27(20.9)$ & $34(26.4)$ & $17(13.2)$ & $51(39.5)$ \\
\hline$>24.9$ & $103(44.5)$ & $42(18.2)$ & $38(16.5)$ & $48(20.8)$ & $46(19.4)$ & $42(17.7)$ & $43(18.1)$ & $106(44.7)$ \\
\hline$p$ value & 601 & & & & .181 & & & \\
\hline
\end{tabular}

$\mathrm{BMI}=$ body mass index.

Table 4

Results of multinomial logistic regression examining the determinants of leisure-time physical activity changes, by sex

\begin{tabular}{|c|c|c|c|c|c|c|}
\hline & \multicolumn{6}{|c|}{ Intensity of physical activity, adjusted OR (95\% CI) } \\
\hline & \multicolumn{3}{|l|}{ Girls $^{a}$} & \multicolumn{3}{|l|}{ Boys $^{\mathrm{a}}$} \\
\hline & Increasing & Decreasing & Stable high & Increasing & Decreasing & Stable high \\
\hline \multicolumn{7}{|l|}{ Parental education (year) } \\
\hline$\leq 6$ & Reference & Reference & Reference & Reference & Reference & Reference \\
\hline $7-9$ & $1.95(.90,4.26)$ & $1.16(.55,2.43)$ & $.63(.26,1.51)$ & $1.04(.35,3.11)$ & $.60(.19,1.85)$ & $1.02(.36,2.88)$ \\
\hline $10-12$ & $1.36(.63,2.96)$ & $.78(.36,1.66)$ & $.90(.42,1.95)$ & $.77(.28,2.13)$ & $.22(.07, .66)$ & $.49(.19,1.28)$ \\
\hline$\geq 12$ & $1.27(.56,2.86)$ & $1.00(.48,2.09)$ & $1.10(.51,2.34)$ & $.52(.19,1.44)$ & $.25(.09, .68)$ & $.46(.18,1.15)$ \\
\hline \multicolumn{7}{|l|}{ Practice of sports at 13 years } \\
\hline No & Reference & Reference & Reference & Reference & Reference & Reference \\
\hline Yes & $1.55(.87,2.77)$ & $2.43(1.39,4.25)$ & $3.96(2.21,7.12)$ & $2.03(.96,4.30)$ & $7.14(3.03,16.78)$ & $6.81(3.30,14.07)$ \\
\hline \multicolumn{7}{|c|}{ Sports competition at 13 years } \\
\hline Never practiced & Reference & Reference & Reference & Reference & Reference & Reference \\
\hline No but already done & $1.29(.69,2.40)$ & $1.36(.74,2.49)$ & $1.92(1.00,3.68)$ & $1.77(.79,4.00)$ & $1.42(.54,3.72)$ & $1.75(.73,4.20)$ \\
\hline Yes & $1.63(.82,3.23)$ & $1.65(.85,3.22)$ & $2.93(1.49,5.77)$ & $1.20(.50,2.90)$ & $1.57(.61,4.03)$ & $4.54(1.97,10.46)$ \\
\hline \multicolumn{7}{|c|}{ Perception of body image at 13 years ${ }^{\mathrm{b}}$} \\
\hline Satisfied & Reference & Reference & Reference & Reference & Reference & Reference \\
\hline Too thin & $.91(.51,1.60)$ & $.58(.32,1.04)$ & $.69(.39,1.23)$ & $.47(.21,1.05)$ & $.42(.17,1.02)$ & $.67(.31,1.44)$ \\
\hline Too large & $.98(.42,2.25)$ & $1.44(.70,2.97)$ & $.58(.23,1.46)$ & $.72(.31,1.69)$ & $.90(.36,2.21)$ & $1.80(.81,4.02)$ \\
\hline \multicolumn{7}{|l|}{ Smoke habits } \\
\hline Never smoker & Reference & Reference & Reference & Reference & Reference & Reference \\
\hline Starting before 13 years & $.62(.32,1.22)$ & $1.23(.67,2.26)$ & $.97(.51,1.85)$ & $1.32(.46,3.78)$ & $3.09(1.16,8.25)$ & $1.84(.73,4.67)$ \\
\hline Starting after 13 years & $1.13(.59,2.19)$ & $1.25(.65,2.42)$ & $1.27(.64,2.49)$ & $1.70(.79,3.66)$ & $.93(.38,2.28)$ & $1.64(.80,3.38)$ \\
\hline \multicolumn{7}{|l|}{ Distances to UGS } \\
\hline$>800 \mathrm{~m}$ & Reference & Reference & Reference & Reference & Reference & Reference \\
\hline$>400 \mathrm{~m}$ to $\leq 800 \mathrm{~m}$ & $1.05(.56,1.96)$ & $.83(.43,1.59)$ & $.81(.42,1.55)$ & $.80(.36,1.79)$ & $1.06(.45,2.53)$ & $.90(.42,1.91)$ \\
\hline$\leq 400 \mathrm{~m}$ & $1.01(.52,1.98)$ & $1.52(.82,2.80)$ & $1.09(.57,2.11)$ & $.93(.42,2.07)$ & $1.16(.49,2.77)$ & $1.08(.51,2.29)$ \\
\hline \multicolumn{7}{|l|}{ Distances to OSS } \\
\hline$>800 \mathrm{~m}$ & Reference & Reference & Reference & Reference & Reference & Reference \\
\hline$>400 \mathrm{~m}$ to $\leq 800 \mathrm{~m}$ & $.61(.33,1.13)$ & $.72(.39,1.33)$ & $.61(.32,1.18)$ & $.93(.44,1.96)$ & $.63(.27,1.43)$ & $.78(.38,1.59)$ \\
\hline$\leq 400 \mathrm{~m}$ & $.53(.26,1.06)$ & $.71(.36,1.39)$ & $1.08(.55,2.14)$ & $.66(.28,1.60)$ & $.72(.29,1.81)$ & $1.10(.50,2.45)$ \\
\hline
\end{tabular}

Bold values represent statistically significant results.

$\mathrm{CI}=$ confidence interval; $\mathrm{OR}=$ odds ratio; OSS = open sport space; UGS = urban green space.

a The reference category is Stable Light, OR Adjusted for parental education and body image at 13 years.

b Too Thin-perceived image was thinner than the desired one; Too Large-perceived image was larger than the desired one. 
contributed to decrease the variability and reduce the strength of the association. Another limitation of our study is the lack of information about perceived characteristics of the urban environment, which could influence the use of the available facilities. However, as the majority of our participants lived in the same residence in both study waves, we expect similar perceptions and consequently a low effect in our results. The strengths of our study include the use of a population-based cohort with repeated measurements of leisure-time PA measured under standardized procedures, as well as repeated measurements of many confounders.

This study found parental education and practice of sports in early adolescence as important determinants of leisure-time PA tracking. We found that UGS and OSS in the vicinity of participants' residence did not impact on changes in PA practice throughout adolescence.

Our results reinforce that programs to promote PA and practice of sports in childhood would be an important intervention against the epidemic of physical inactivity at later ages, especially among those with lower levels of leisure-time PA, such as girls, and those with more disadvantaged socioeconomic conditions.

\section{Acknowledgments}

The authors acknowledge PortoLazer from Porto council for providing a list of all sports spaces of Porto city and Roseanne Autran for the field survey to georeference the sports facilities.

Authorship Criteria: A.M. participated in the study design, conducted the analysis and interpretation of the data, and wrote the article. M.F.P. and E.R. participated in the study design, participated in the interpretation of data, revised the manuscript, and approved the final version to be published.

\section{Funding Sources}

This work was financed by FEDER funds through the Programa Operacional Factores de Competitividade-COMPETE and by Portuguese funds through FCT-Fundação para a Ciência e a Tecnologia in the framework of the project POCTI/SAU-ESP/ 62399/2004 and FCOMP-01-0124-FEDER-015750.

\section{References}

[1] Lee IM, Shiroma EJ, Lobelo F, et al. Effect of physical inactivity on major non-communicable diseases worldwide: An analysis of burden of disease and life expectancy. Lancet 2012;380:219-29.

[2] Kirk D. Physical education, youth sport and lifelong participation: The importance of early learning experiences. Eur Phys Educ Rev 2005;11:239-55.

[3] Jose KA, Blizzard L, Dwyer T, et al. Childhood and adolescent predictors of leisure time physical activity during the transition from adolescence to adulthood: A population based cohort study. Int J Behav Nutr Phys Activity $2011 ; 8: 54$

[4] Hallal PC, Andersen LB, Bull FC, et al. Global physical activity levels: Surveillance progress, pitfalls, and prospects. Lancet 2012;380:247-57.

[5] Sallis JF, Prochaska JJ, Taylor WC. A review of correlates of physical activity of children and adolescents. Med Sci Sports Exerc 2000;32:963-75.

[6] Metcalf BS, Hosking J, Jeffery AN, et al. Exploring the adolescent fall in physical activity: A 10-yr cohort study (EarlyBird 41). Med Sci Sports Exerc 2015;47:2084-9.

[7] Simpkins SD, Schaefer DR, Price CD, et al. Adolescent friendships, BMI, and physical activity: Untangling selection and influence through longitudinal social network analysis. J Res Adolesc 2013;23.

[8] Allender S, Cowburn G, Foster C. Understanding participation in sport and physical activity among children and adults: A review of qualitative studies. Health Educ Res 2006;21:826-35.

[9] Farias Junior JC, Reis RS, Hallal PC. Physical activity, psychosocial and perceived environmental factors in adolescents from Northeast Brazil. Cad Saude Publica 2014;30:941-51.
[10] Payne S, Townsend N, Foster C. The physical activity profile of active children in England. Int J Behav Nutr Phys Activity 2013;10:136.

[11] Mota J, Santos MP, Ribeiro JC. Differences in leisure-time activities according to level of physical activity in adolescents. J Phys Act Health 2008;5:286-93.

[12] McGrath LJ, Hopkins WG, Hinckson EA. Associations of objectively measured built-environment attributes with youth moderate-vigorous physical activity: A systematic review and meta-analysis. Sports Med (Auckland, NZ) 2015;45:841-65.

[13] Heath GW, Parra DC, Sarmiento OL, et al. Evidence-based intervention in physical activity: Lessons from around the world. Lancet 2012;380: 272-81.

[14] Hume C, Salmon J, Ball K. Children's perceptions of their home and neighborhood environments, and their association with objectively measured physical activity: A qualitative and quantitative study. Health Educ Res 2005;20:1-13.

[15] Witten K, Hiscock R, Pearce J, et al. Neighbourhood access to open spaces and the physical activity of residents: A national study. Prev Med 2008;47: 299-303.

[16] Ord K, Mitchell R, Pearce J. Is level of neighbourhood green space associated with physical activity in green space? Int J Behav Nutr Phys Activity 2013;10:127.

[17] Davison KK, Lawson CT. Do attributes in the physical environment influence children's physical activity? A review of the literature. Int J Behav Nutr Phys Activity 2006;3:19.

[18] Hunter RF, Christian H, Veitch J, et al. The impact of interventions to promote physical activity in urban green space: A systematic review and recommendations for future research. Social Sci Med (1982) 2015;124: 246-56.

[19] Ramos E, Barros H. Family and school determinants of overweight in 13-year-old Portuguese adolescents. Acta Paediatr 2007;96:281-6.

[20] Helmerhorst HJ, Brage S, Warren J, et al. A systematic review of reliability and objective criterion-related validity of physical activity questionnaires. Int J Behav Nutr Phys Activity 2012;9:103.

[21] Stunkard AJ, Sorensen T, Schulsinger F. Use of the Danish adoption register for the study of obesity and thinness. Res publications - Assoc Res Nervous Ment Dis 1983;60:115-20.

[22] Almeida S, Severo M, Araujo J, et al. Body image and depressive symptoms in 13-year-old adolescents. J Paediatr Child Health 2012;48:E165-71.

[23] Araujo J, Barros H, Severo M, et al. Longitudinal changes in adiposity during adolescence: A population-based cohort. BMJ Open 2014;4:e004380.

[24] Kuczmarski RJ, Ogden CL, Guo SS, et al. 2000 CDC growth charts for the United States: Methods and development. Vital Health Stat 11 2002:1-190.

[25] Clinical guidelines on the identification, evaluation, and treatment of overweight and obesity in adults-the evidence report. National Institutes of Health. Obes Res 1998;6 Suppl 2:51S-209S.

[26] Sallis JF. Neighborhood Environment Walkability Scale (NEWS) Available at: http://sallis.ucsd.edu/measure_news.html. Accessed 12 May 2014

[27] Spengler S, Woll A. The more physically active, the healthier? The relationship between physical activity and health-related quality of life in adolescents: The MoMo study. J Phys Act Health 2013;10: $708-15$.

[28] Stuntz C, Weiss M. Motivating children and adolescents to sustain a physically active lifestyle. Am J Lifestyle Med 2010;4:433-44.

[29] Sirard JR, Pfeiffer KA, Pate RR. Motivational factors associated with sports program participation in middle school students. J Adolesc Health 2006;38: 696-703.

[30] Iannotti RJ, Chen R, Kololo H, et al. Motivations for adolescent participation in leisure-time physical activity: International differences. J Phys Act Health 2013:10:106-12.

[31] Lee AC, Maheswaran R. The health benefits of urban green spaces: A review of the evidence. J Public Health (Oxford, England) 2011;33:212-22.

[32] Pikora T, Giles-Corti B, Bull F, et al. Developing a framework for assessment of the environmental determinants of walking and cycling. Soc Sci Med (1982) 2003;56:1693-703.

[33] Autran RG, Ramos E, Pina Mde F, et al. The association between proximity to sports facilities and participation in sports among 13-year-olds in the city of Porto, Portugal. Cad Saude Publica 2012;28:549-58.

[34] Strom MA, Silverberg JI. Associations of physical activity and sedentary behavior with atopic disease in United States children. J Pediatr 2016;174: 247-253.e243.

[35] Pemde HK. Body image in adolescents - A clinical issue. Indian J Pediatr 2015:82:1086-8.

[36] O'Dea JA, Abraham S. Improving the body image, eating attitudes, and behaviors of young male and female adolescents: A new educationa approach that focuses on self-esteem. Int J Eat Disord 2000;28:43-57.

[37] Brown JD, Witherspoon EM. The mass media and American adolescents' health. J Adolesc Health 2002;31:153-70.

[38] Cohane GH, Pope HG Jr. Body image in boys: A review of the literature. Int J Eat Disord 2001;29:373-9. 